\title{
Progress in Study on the Unevenness of Slivers and Yarns in Japan
}

\author{
By Kazuo Mihira, Member, TMS \\ Faculty of Home Economics, Japan Women's University, Tokyo
}

\section{Introduction}

Spinning mills have to control and keep spinning processes as stationary as possible so as to insure uniformity in the counts of slivers and yarns, in the number of fibers in the cross-section, in twist number, etc.

In spinning processes, short-length fibers are scattered once in the open air, collected again, arranged in their longitudinal direction and made into very long bundles. Fiber bundles are of ten made uneven owing to mechanical disorder of spinning machines and the characteristics of fibers, i.e., the distribution of the length and fineness of fibers, the shapes of fibers, the coefficient of friction, the moisture content, the mechanical properties of fibers and so forth.

Control of the irregularity of fiber bundles and yarns is, therefore, a complicated task. Yet it is as imperative a task as the control of spinning machines and the quality control of production.

Spinning engineers have always been seriously interested in the process of converting masses of fibers of into, successively, lap, slivers and yarns and explored the possibilities of improving this process. Reduction of fiber-bundle unevenness to a minimum requires mechanical study looking to improvements in spinning machines (speed-up, vibration reduction, motive power adjustment, etc.). However, the main subject of this article is the behavior of fiber groups treated by machine. The article is divided into three parts.

The first part seeks to grasp the principle of spinning and, by analyzing fiber motions, to locate the causes for unevenness. The second part analyzes the unevenness of products and, in the light of this analysis, presumes the principle of spinning and, at the same time, seeks to devise steps to control unevenness. The third part aims to grasp the unevenness of products, estimate their quality and detect mechanical unevenness which is generated during spinning.

The article also presents a history of the progress in Japanese spinning techniques and reviews in detail individual researches behind these techniques.

\section{First Stage in Study on Unevenness}

Japanese spinning engineers developed interest in the quality control of products, especially control of unevenness of slivers and yarns, and began study. ing it not long ago. Long before that, data based on the experience of successive generations of engineers, plus such additional data as were obtained in course of time, were just about the only guide. Those data were obtained mostly by intuition born of great skill. For instance, the only method to measure unevenness was to cut slivers or yarns in a uniform length, weigh them, and repeat this procedure again and again.

If irregularity of sliver weight was great, certain parts of the drawing frame, card or mixing and scutching machine were adjusted, but what parts to adjust and how could be decided only by an expert with high skill and keen intuition. The degree of unevenness was judged by looking at produced yarns; if irregularity was great, a remedy was attempted by changing the relative humidity, replacing drafting parts and by other conceivable means haphazardly. Many irregularity problem were, therefore, left unsolved. Yet such a control method is used, though in a systematic way, in some mills even today.

A spinning mill of today operates on a large scale and produces many different products systematically and in large quantities. Before 1930 or thereabouts, however, the variety of products turned out by a spinning mill was small, and many operational troubles were left unsolved. In those days, imported raw materials for textiles were not uniform in kind or quality, with the result that a diversity of spun yarns were produced in small amounts. It was difficult, therefore, to conduct long-term researches or experiments on any one kind of raw meterial. Hence hardly any basic study on spinning 
was made.

In 1936 Mori[1] devised the first Japanese instrument to estimate the unevenness of fiber bundles. He had experimented by recording the unevenness of yarns and other products with an air micrometer, and then devised an electric integrator to express the degree of unevenness automatically from recorded results. This valuable instrument was never put to practical use, however. Conditions in the Japanese spinning industry were not ripe for that. Indeed, some researchers were skeptical of the possibility of scientific estimating or analysis of unevenness, which was influenced by numerous factors. Other researchers thought it was all right to study unevenness, but were indifferent to such study.

Another reason why inquiry into unevenness made little, if any, headway was that manufacturers of textile testers did not participate in it. Still another reason was that seriplane test was made much of as a means to estimate yarn unevenness, as was the case in the silk-reeling industry.

A fact which should not be left unnoticed is that consumers did not take unevenness as seriously as they do today, even though unevenness had an important bearing on yarn quality.

Perhaps this was natural, since the bulk of spun yarn production was coarse or medium count, and the degree of unevenness was a matter of slight consequence to users of yarns. Unevenness was no pressing problem until modernization of the Japanese spinning industry compelled a shift of production from coarse to fine yarn counts. In those days, yarns were spun by experience and as. siduous exertions, and the cloths made of those yarn were sewn manually, the seamster omitting defective or unsightly parts of the cloth.

If a large quantity of cloth was cut at one time for mass-production of ready-made dresses, accidental defects were noticed which would make the dresses look poor.

\section{Studies on Drafting Curve}

Systematic study of unevenness began in Japan during the closing days of World War II. In what follows I shall give a history of progress in studies on the principle of spinning, especially on the drafting principle and unevenness. In 1944 Ishikawal2] stressed the need for a drafting principle and set about organizing one. $\mathrm{He}$ and his friends had sought to elevate the spinning technique from some- thing based merely on experience to something founded on theory. Ishikawa's aim was not so much to devise measures to combat unevenness of slivers and yarns but to observe the mechanism of the fiber motion and thereby improve the drafting unit with a view to more uniform drafting and more uniform goods. His way of thinking was a "revival" of a thought expounded by Gooding in 1931 .

Ishikawa's discussions were, therefore, limited to an ideal sliver, i.e., a uniform sliver or yarn having an ideal arrangement of ideally shaped fibers. For the first time, he quantitatively made clear what motion fibers would make if ideal slivers were ideally drafted. He divided moving fibers (fibers which moved by drafting) into three groups: "a low-speed motion group," a "high-speed motion group" and a "floating group." This division forms the basis of the drafting theory of today that a fiber moves through all the three groups during drafting.

Ishikawa, however, interested himself in the socalled "ideal draft" in which fibers of the "floating group" made a uniform motion at the same speed as fibers of the "low-speed motion group." He found out the distribution of tufted fibers in the draft zone and the trend of decrease in the fiber density in the draft zone, and theoretically called that trend a "drafting curve." This is essentially the same as today's theory, but it was featured by Ishikawa's own geometrical representation and drafting curve which was calculated mathematically and clearly given.

Actually, an ideal sliver does not exist. Drafting by the roller drafting system of drafting increases the unevennes of fed slivers. Where the roller drafting system is used, ideal drafting is the only way to keep the unevenness of produced slivers from exceeding the unevenness of bad slivers.

In 1952 Ikedal3] took over Ishikawa's work but developed Ishikawa's geometrical analysis intact. In 1955 Ikeda and Kinoshita[4] substituted a model of the fiber motion almost equivalent to the motion of ordinary fibers, and referred qualitatively to floating fibers and their motion in the draft zone, especially the mechanism of the outbreak of unevenness in drafting and the unevennes of drafted slivers.

In 1948 Watanabe[5] suggested a method to represent the irregularity of sliver thickness. It was called a "sliver diagram" and was capable of expressing the irregularity of ordinary slivers geometrically. The "sliver diagram," again, was capble of explaining Ishikawa's dissertation succinctly and proved a useful model for the analysis of drafting. 
Watanabe's method was developed into Hirako's drafting theory[6] of 1958 on the solid sliver diagram. Hirako aimed to analyze unevenness occurring during drafting and to devise steps to counter it.

Reasonable assumptions are a key to explaining the behavior of floating fibers. Ishikawa's assumption on ideal drafting was inconsistent with practice. A need arose for an assumption that floating fibers had a variable speed. There was a simmer of discussion about this assumption in the early 1950's.

Ichino and Kurosaki's 1956 experiment[7] which traced the behavior of floating fibers in the draft zone, Shirakashi and Tabata's experiment $[8]$ in the same year, Fujino, Shimotsuma and Masui's[9] and Yamaguchi's[10] were all aimed to grasp the actua. lities of the fiber motion by inserting dyed fibers into slivers and to formulate reasonable assumptions. Ichino found out experimentally the fiber speed under various conditions (roller gauge, draft ratio, etc.). In 1957 he and Goto[11] dynamically studied the fiber motion during drafting.

In 1948 Narita[12] statistically explained the drafting mechanism. He represented the nip curve of a sliver as a general equation stochastically, irrespective the distribution of the fiber length, found out the drafting mechanism of ideal state and established a general equation by which the drafting curve was given as the function of the draft ratio, roller gauge and the mean value of the fiber length of fed slivers. Unlike Ishikawa, Watanabe and others, Narita used no geometrical representation. Narita's method of analysis led to the growth of statistical studies on spinning later.

\section{Studies on the Theory of Irregularity of Fiber Bundle and Application of the Theory}

Tippett's enlightening report has aroused an ever-increasing interest in Japan in the use of statistics in textile engineering since 1931. Studies on the mean value and deviation of samples have been made by Kida[13], Hoshino[14] and others. In 1951 Uchida, Narita and Mihira[15] started studying theoretically the irregularity of the thickness of slivers and yarns. They applied the stochastic process theory to these studies for the first time. After World War II, Japanese engineers and researchers in machinery, aircraft and electricity participated in the study of spinning. This has facilitated the introduction of applied mathematics and helped in the production of measuring instruments of high accuracy.
Uchida, Narita and Mihira's method to represent unevenness by the stochastic process had the purpose of representing the unevenness of the thickness of slivers and yarns as the function of the length. By a long initial series of experiments they proved that the unevenness of slivers and yarns was an object of the stationary and normal stochastic process.

They succeeded in establishing a theoretical equation showing the relation between deviation and test length by applying the concept of autocorrelation to variations of thickness. The equation shows that the parameter itself is a measure of the degree of irregularity.

This theory stemmed from the assumption of the simple Markov process or the double Markov process; it proved useful in finding the theory of the Variance-Length curve (V-L curve). Uchida, Narita and Mihira pointed out that it was proper to estimate unevenness with the parameter in a theoretical equation representing the V-L curve. They indicated that doubling and drafting effects could be explained by the V-L curve.

Furthermore, Narita and Mihira suggested analyzing, with time series, the unevenness diagram of the weight of slivers and yarns or the unevenness diagram of their thickness. Through this suggestion Narita and Mihira won many collaborators. At that time, active interest in systematic researches and studies was growing in Japan. Japanese mills began to put to practical use the series of weight unevenness in various drafting processes and the unevenness diagram recorded by unevenness testers. Mill engineers, however, were not satisfied with merely observing the series and curves.

Correlogram analyzers were made by Narita and Mihira[15] in 1951, by Shirakashi, Mihira and Kazama [16] in 1954 and by Mihira[17, 18] in 1956 and 1957. A spectral density analysis of the moving average of the unevenness of slivers drawn by the drawing process, and a harmonic analysis of such slivers, were tried by Shirakashi, Mihira and Kazama. Similar analyses of the unevenness of yarns spun by direct spinning were tried by Shirakashi, Tabata and Numano[19] in 1951. Special features of these analyses are given in section 5 of this article.

Many studies on the unevenness of the number of fibers in the yarn cross-section were also made. The concept of random slivers as the roulette model, enunciated by Martindale, was accepted with interest in Japan. Random slivers, instead of ideal slivers and sliver diagram, turned out to be very useful for minute theoretical study. 
In 1953 Uchida, Mihira and Ikeuchi[20] represented, by a general equation culculated with probability, the distribution of tufted fibers, the distribution of length deviation and other aspects of random slivers. They found out the autocorrelation function theoretically and compared the theoretical curve giving the relation between variance and test length with experimental results[18].

In 1954 Tabata and Ishikawa[21] emphasized that the unevenness of sliver thickness was due to an irregular arrangement of the ends of fibers in a sliver. This subject is dealt. with in section 5 .

In 1957 Fujino and Kawabata[22] pointed out that the character of sliver unevenness could be explained by representing the unevenness in the spectral density, and made a theoretical study of the spectral density relating to the arrangement of fibers in random slivers.

Fujino and Kawabata thought it was difficult to explain the relations between the drafting mechanism and drafting irregularity by the conventional statistical methods based on the concept of geometry, mean value and variance. They sought to find a third method, and defined a new sliver function so that the function of spectral density might be represented by the fiber arrangement in slivers. The report of their studies proved helpful to later studies of spinning. Of this more in section 5 .

Theoretical studies on unevenness have been made in Japan since 1950. Mill engineers were made aware of the need for statistics because the quality control method of $3 \sigma$ was recommended. They gradually came to understand the theory of irregularity and made their many requirements and suggestions known to researchers. This is how the theory of the drafting mechanism and practical study of it have been developed.

\section{Unevenness Testers and Their Use}

Unevenness testers were trially produced and studies of them made in line with studies on the unevenness of slivers and yarns. The study by Mori[1], already referred to on an unevenness tester which used air micrometer was resumed by Shira. kashi and Yam aguchi[23] in 1951. This highly accurate measuring instrument had been carefully studied by mechanical engineers during World War II. It was handy for estimating the unevenness of the thickness of slivers and yarns and was produced by the Government Industrial Research In- stitute, Nagoya in 1953 and later by Shimadzu Sei. sakusho Ltd. and Kosth Measuring Instruments $\mathrm{C}_{0}$., Ltd. It is now widely used.

Measuring instruments using electricity or radioisotope were also studied, but only the air micrometer type came into practical use. Shirakashi, Yamaguchi and Mori, who suggested the air-micrometer type instrument, studied and published a method to estimate the unevenness curve recorded by the instrument. They also devised an automatic calculating unit. Using these devices, they represented the variations in the unevenness curve with a parameter by a point system so that the results might be nearly equivalent to seriplane test results. But this method of testing has not come into general use.

A school of opinion has it that seriplane test is subject to the personal errors of inspectors, because the test is made by eyesight. However, seriplane test judges not only the unevenness of yarn thickness but also the magnitude of fluff and nep. Fluff and nep are not to be taken as a special form of unevenness, but should be distinguished qualitatively from unevenness.

Studies on fluff and nep have been made. Fluffand nep-measuring instruments equipped with a photoelectric cell were invented by Narita, Mihira[15] and Fujino[26] in 1948 and by Mihira and Sugimoto[27] in 1958, and put in practical use. Mihira found out a new hairiness density curve. It is a distribution function given by the density of fiber tufts measured from the surface of the yarn body to the outside. It is similar to the tuft diagram of fiber length. Several researchers are still studying methods to measure and estimate fluff.

More and more importance was attached to studies on fluff in consequence of troubles accompanying the shortening or speed-up of the spinning processes and also of the poor appearance of yarns and cloth pilling caused by synthetic fiber spinning or blending of synthetic fibers. Recently, a method to analyze periodical unevenness on seriplane was devised by Takai[28]. He analyzed patterns formed on panels by yarns having periodical unevenness and succeeded in explaining the relation between the spectrum of yarn unevenness and the patterns.

Correlogram was the first thing used in Japan in the study of instruments to analyze unevenness diagrams. In 1957 Mihira[29] trially made a correlator based on Martindale's correlation periodgraph with some improvements. Shimizu[30] also made a similar instrument on trial. He analyzed unevenness diagrams and also sought the autocorrelation of web and others on the unevenness panel. Mihira[29] 
published an experiment by which an unevenness diagram was expressed as the wave-length of a period and amplitude. Besides, there has since been trial production of instruments to analyze moving mean values. One such instrument is a unit to cancel low-frequency variations in unevenness diagrams. Anoter is a unit to extract variations of high frequency.

\section{Studies on Unevenness by Drafting and Sliver Unevenness}

This section is closely related to sections 2 and 3 because researchers who made the various studies in those sections undertook researches covered in the present section.

Ikeda and Kinoshita[4] explained, by geometrical representation, the relation between a staple diagram and the wave-length of unevenness induced by drafting. The degree of the unevenness of produced slivers depended, in their opinion, on the number of floating fibers in the draft zone, on the range of reach of the draft force of the front roller and on the proportion of the high-speed floating fibers to all fibers.

Narita and Mihira[15] indicated, with the aid of equations relating to variations and test length, that the coefficient of variations in sliver unevenness induced by doubling was theoretically small; that autocorrelation did not vary; but that the reciprocal variations of draft ratio were added to the unevenness of produced slivers if drafting irregularity occurred.

In Japan attempts to explain draft by assuming drafting-induced unevenness began with Tabata and Ishikawa[21] who in 1954 dynamically explained draft in its relation to sliver construction. Fujino and Kawabata substituted modern mathematical representations for these attempts with good results. Tabata and Ishikawa thought of sliver unevenness as a component made up of clusters of fibers, as I have already said. They found the drafting-induced motions of those fiber clusters according to various types of distribution of change-points of the speed of the fiber clusters and calculated theoretically the unevenness of produced slivers which was caused by functional variations in the density of the ends of the fibers in the sliver. Here, the unevenness of produced slivers is represented as the square of the coefficient of variations.

Yamaguchil32], however, thought that the actualities of irregular draft could not be explained only by the distribution of change points of the fiber speed. He looked into the types of irregular draft by tracing dyed fibers and indicated the characteristics and the importance of the behavior of clusters of fibers. Tabata and Ishikawa used statistics in their representation and, therefore, represented the average of various fiber motions. Yamaguchi explained peculiar processes with examples. Yamaguchi's explanation was, therefore, qualitative and incapable of calculating the degree of sliver unevenness.

Fujino and Kawabata, like Tabata and Ishikawa, represented the phenomena of draft by the trans. formation of the fiber arrangement. However, they considered the statistical representation by Tabata and Ishikawa inadequate for quantitative re. presentation and developed the draft theory by seeking quantitatively the qualitative representation of Yamaguchi.

Fujino and Kawabata represented the arrange. ment of the ends of fibers by three elements: the density of the tips of fibers, the density function of tips and the distribution function of the distance between tips. Fujino and Kawabata considered these elements individually or together, depending on the purpose of draft analysis, and succeed in mathematically converting fiber arrangement into sliver unevenness. They applied the transfer function of linear transfer elements to the sliver function already mentioned.

Furthermore, Fujino and Kawabata obtained the sliver function of slivers having different distributions of fiber length and calculated drafting-induced unevenness on a typical model of the density function of the tips of fibers. If the peculiar process of drafting-induced unevenness shown by Yamaguchi is represented by the density function of the tips of fibers, then the transition phenomena of drafting. induced unevenness can be theoretically explained. Yamaguchi's study is, therefore, valuable because it deduces theoretical explanation of draft from a spectral representation of unevenness induced by drafting.

\section{Studies on Drafting Unit and Sliver Unevenness}

Sliver unevenness is fairly often produced by mechanical variations in the drafting unit and also by causes referred to in the previous sections. We therefore, have to study the relation between various mechanical factors, which bring on mechanical var. iations, and sliver unevenness. Such a study has 
been systematically made since the mid-1950's when measuring instruments to detect the mechanical variations came into use. However, study on methods to represent sliver unevenness was incomplete then and a detailed analysis of unevenness was fairly troublesome. Accordingly, measured values of unevenness was represented merely as variance or U\% of unevenness diagram. A minute study was made, however, of the apron device which was the main part of the drafting unit, because improvement of the apron was a short cut to high draft or the speed-up of production.

In 1955 Fujino, Shimotsuma and others[33] began to study the pressure distribution of the apron and analyzed the apron slip and the irregularity of the apron speed. Noda, Miura and Matsumoto[34] experimentally examined the relation between the pressure distribution of the apron and yarn unevenness in $1955 . \quad$ Earlier, in 1954, Takizawa, Imamura and Kobayashi[35] looked into the influence of the irregularity of the apron speed, the apron slip, etc. on drafting-induced unevenness. Similar studies were also made by Kato and Ishihara[36].

Besides, study on variations in drafting rollers developed as rubber-rollers came into wide use and machines were speeded up. In 1952 Fujino and Harikawa[37] analyzed in detail and theoretically the relation between the eccentricity of top rollers and the bound, and examined the influence of this relation on yarn unevenness. Variations in drafting rollers are caused also by the practical value of the draft ratio with the increase of the draft zone. Accordingly, the relation between the draft ratio and sliver unevenness was studied. The draft ratio has also a relation to drafting force as well as to rollers. Therefore, fluted rollers were studied at the same time.

In 1948 Uchida, Takizawa, Tabata and others[38] obtained experimentally the best draft ratio for draw. ing from the degree of sliver unevenness and suggested a reasonable draft ratio. In 1955 Ogawa[39| made a detailed and experimental study of drawing frames and spinning frames. In the same year, Watanabe[40] analyzed theoretically the infuence of roller slip on unevenness induced by drafting. Shirakashi and Tabata[41] examined sliver unevenness caused by the periodical change of the weight of the top roller of the spinning frame. Ogawa[39] made a general examination of various synthetic materials for top rollers. Similar researches were made by Kaino[42] in 1953, by Noda[43] in 1955 and by many others later.

Twist vibrations of the bottom roller were studied by Ishikawa and Higuchi[44] in 1952 and by Kamo- gawa and Higuchi[45] in 1957. The studies were discontinued when it was found that the influence of twist vibrations on unevenness induced by drafting was slight.

Later, however, a method to measure draft force by using the torque of the roller was looked into. In 1959 Shimizu[46] ascertained that variations in draft force measured by this method was closely related to the unevenness of produced slivers. In 1957 Ogawa and Ishihara[47] measured draft force and compared it with the irregularity of the yarn aspect. The relation between the irregularity of the surface speed of rollers and sliver unevenness was studied dynamically by Yamagishi, Furuyama and Kuroe[48] in 1955.

In 1956 Itani[49] inquired into the irregularity of the fiber arrangement of slivers. It was a general study on the degree of the arrangement and dealt partly with the relation of this irregularity to sliver unevenness.

\section{Studies on the Unevenness of Produced Top and Yarn in Draft Cut Spinning}

The Perlock system spinning in Japan has developed as a two-line system since 1925 and experimentally used in many mills. Study on the Perlock system spinning was started by Nakayama[50] in 1943 and became an object of interst to many researchers.

Initial theoretical studies were mainly aimed to explain the draft-cut mechanism. Later, in 1951, Amano [51] obtained the distribution of the length of draft-cut fibers. Ishikawa and Tabata[52] developed it theoretically in 1952. Fujino and Horikawa[53] pursued theoretical development still further; they investigated the physical behavior of one long fiber drafted and cut in the draft zone and the draft cut mechanism. In other wards, they sought to explain the fiber length of produced top.

Hayakawa[54], Ishikawa and Tabata[52] obtained the distribution and variance of fibers in the draftcut zone in 1950 . Their study makes a contrast to that on the draft curve in the ordinary draft zone. Narita[55] obtained statistically the draft curve of draft-cut as a special solution of the draft curve. Uchida, Mihira and Ikeuchi[20] obtained by probability the nip distribution of front and back rollers. Mihira suggested the draft-cut model, instead of the roulette model or the model of spinning nozzle of Van den Abeel, as a model of random slivers. He calculated stochastically the distribution 
of the fiber length of top produced by the double draft-cut system and the roller gauge matching the double zone.

Fujino and Horikawa also analyzed the same problem in detail by making geometrical calculation stochastically. Furthermore, in contrast to the ideal draft-cut, a practical study had to be made of unevenness occurring in the draft-cut zone. Many theoretical and experimental studies emerged.

In 1952 Ishikawa and Tabata[52] studied theoretically the mechanism of the outbreak of unevenness by basing their inquiry on the density distribution of the tips of fibers tufted by back rollers, and explained the accidental decrease and stabilization of the irregularity of cut length in the draft-cut mechanism. Also in 1952 Fujino and Horikawa[53] studied this irregularity with a sliver diagram on the possible maximum of fibers and the shape of top unevenness caused by the accidental irregularity of cut length.

As for experimental studies, Uchida, Takizawa and others[56] made a voluminous study consisting of 11 reports from 1950 . Shirakashi and Yamaguchi[57] found in 1952 that the character of unevenness induced by draft-cut was not the same as the character of unevenness caused by the ordinary draft. They pointed out that the method to estimate one type of unevenness should be different from the method to estimate the other type of unevenness. However, from 1953 to 1954, Shirakashi, Tabata and Numano[19] and Ishikawa, Tabata and Okubo[58] estimated, by analyzing the spectral density, the unevenness of yarn spun by the direct spinning system and reported on the character of draft-cut unevenness.

Besides, as a special experiment, Mihira[59] devised the double draft-cut system by adding dispersive weak points to tow, stochastically explained the draft-cut mechanism and made a periodical analysis of produced top. In 1957 Hirako[60] sug. gested a spinning method which jetted heated vapor to a special point in the draft-cut zone, and explained its draft-cut mechanism. These led to inquiry into the problem of converting tow into top with the cutter in Japan.

\section{Other Studies}

Studies on the irregularity of blending and automatic control were other major efforts to solve the unevenness problem.
The need for studies on the irregularity of blending has been specially emphasized with the development of synthetic fibers. Studies on this subject are, therefore, of comparatively recent origin.

In 1954 Ishikawa, Shimizu and Haneda[61] analyzed the irregularity of the blending ratio of a blended yarn containing wool, viscose rayon staple and acetate staple by dissolving the fibers in chemicals. They examined with correlogram the unevennes diagram of the yarn before and after treatment, and succeeded in locating the influence of the gilling process on drafting-induced unevenness. In 1955 Fuchino and Ueno[62] counted the number of fibers in the crosssection of blended slivers consisting of cotton and rayon staple, and found that the variance coefficient of blending depended on the fineness of rayon staple.

In the same year Ishikawa and Shimizu[63] tried to study the irregularity of blending theoretically and experimentally again, and indicated that the fiber arrangement in blended slivers, like the fiber arrangement in slivers assumed by Cox, made Poisson's distribution. They also indicated theoretically the tendency of the relation between sliver doubling and the irregularity of blending. In 1954 Osawa[64] reported experimentally that the drawing process improved the irregularity of blending. Ishikawa and Kurusu[65] had previously said the same thing.

It is not enough to represent the irregularity of blending only by the proportion of fibers in the crosssection. It is necessary to represent the cluster of the same kind of fibers in yarn. Fuchino and Ueno[62] suggested a method to analyze the blending ratio in detail by dividing slivers or yarns into concentric circle zones. However, stochastic representation and dynamical variations of different fibers in the drafting process still await inquiry.

Finally, about automatic control. Cards and drawing frames having automatic control equipment to correct the unevenness of lap and slivers positively have been around. Their efficiency has been studied from its relation to sliver unevenness. In 1958 Murakami, Shoman and Kase[66] found theoretically, for the first time, how far automatic control equipment could improve sliver unevenness. They represented sliver unevenness as the remaining rate of unevenness and this was done mainly to investigate the transition phenomena. They reported theoretically on open loop, closed loop and combined use of the two.

In 1960 Mihira and Takeda[67] put in practical use a method to detect sliver unevenness with a new frictor and produced simple automatic control equip. 
ment on trial. They found the spectral density of sliver unevenness based on sliver correlogram and calculated the variance of improved slivers by obtainging the transfer function experimentally.

Also in 1960 Sato, Ihara and Miyashita[68] tried to obtain theoretically the V-L curve of slivers controlled automatically. They[68] expounded the concept of automatic control in the analysis of the fiber motion in the roller draft zone and tried to explain the draft mechanism. Its theory was amplified in 1959 by Shimizu[69], who produced on trial control equipment which had a front roller which doubled as a detector. He succeeded in eliminating shortterm unevenness before and after draft wave. He explained the draft mechanism by representing mainly the nip distribution as Ihara did.

Also in 1959 Kawabatal70] explained the draft mechanism by deducing the concept of automatic coutrol of the density of fiber tips mainly. Mihira and Takeda[67] suggested simple control equipment having two frictors on the back roller of the spinning frame, for the control of short-term unevenness of slivers, one frictor tufting slivers and the other detecting and controlling sliver unevenness. The equipment has a control system in which the density distribution of fiber tips, based on Kawabata's distribution theory, and the influence of draft resistance are contained in transfer function.

Studies on the analysis and control of the unevenness of the thickness of slivers and yarns have produced good results, but the problem of the irregularity of yarn twist still remains largely unsolved. Uchida, Narita and Mihira[15] measured the twist irregularity of ring yarn and mule yarn, and obtained the V.L curve by correlogram analysis. In addition, Uno[71], who studied a method of continuous detection of twist irregularity for control, is making further theoretical and experimental studies on twist irregularity.

\section{Conclusion}

1 have reviewed the history of researches on the unevenness of slivers and yarns in Japan since 1940. These researches have become very active in only 10 years, like studies in other fields of science, and have undeniably been stimulated by the remarkable progress of science in these years. Studies on unevenness have undoubledly been the most important contributing factor to the development of spinning.

\section{Literature cited}

[1] H. Mori ; Journal of the Textile Industrial Society of Japan (Seni Kogyo Gakkai Shi) 2, 368 (1936)

[2] S. Ishikawa; J. Soc. Text. \& Cellulose Ind., Japanese ed., 1, 100 (1944)

[3] A. Ikeda ; ibid., 7, 476, 525 (1951)

A. Ikeda; ibid., 8, 12, 108, 287 (1952)

[4] A. Ikeda and M. Kinoshita; J. Text. Mach. Soc. Japan, Japanese ed., 8, 475 (1955)

[5] S. Watanabe; ibid., 1, 135 (1948)

[6] R. Hirako; ibid.,

[7] T. Ichino and S. Kurosaki; J. Soc. Text. \& Cellulose Ind., Japanese ed., 12, 19, 21 (1956)

[8] K. Shirakashi and M. Tabata; Reports of the Japan Cotton Technical Institute, No. 51 (1956)

[9] K. Fujino, Y. Shimotsuma and Y. Masui ; J. Text. Mach. Soc. Japan Japanese ed., 9, 440 (1956)

[10] M. Yamaguchi; ibid., 10, 8, 341 (1957)

[11] T. Ichino and T. Goto; J. Soc. Text. \& Cellulose Ind., Japanese ed., 10, 107, 257 (1954)

[12] Y. Narita ; ibid., 4, 24, 92 (1948)

[13] T. Kida; Lecture on Staple Fiber

[14] K. Hoshino; Bulletin of the Toyo Rayon Co., Ltd.

[15] Y. Narita and K. Mihira; J. Soc. Text. \& Cellulose Ind., Japanese ed., 7, 191 (1951)

H. Uchida, K. Mihira and Y. Narita ; ibid., 7, 252, 310, 586 (1951)

H. Uchida, K. Mihira and Y. Narita ; ibid., 8, 111, 186, 249, 299 (1952)

[16] K. Shirakashi, K. Mihira and K. Kazama ; ibid., 10. 55 (1954)

[17] K. Mihira ; J. Text. Mach. Soc. Japan, Japanese ed., 6, 283,351 (1953)

K. Mihira ; ibid., 9, 225, 307, 801 (1956)

[18] K. Mihira ; J. Soc. Text. \& Cellulose Ind., Japanese ed., 13, 656, 756 (1957)

[19] K. Shirakashi, M. Tabata and Y. Numano; Unpublished.

[20] H. Uchida, K. Mihira and Y. Ikeuchi; J. Soc. Text. \& Cellulose Ind., Japanese ed., 9, 500, 541 (1953)

[21] M. Tabata and S. Ishikawa; ibid., 10, 344, 471 (1954) M. Tabata and S. Ishikawa; ibid., 11, 181 (1950) M. Tabata and S. Ishikawa; ibid., 13, 87, 354, 390 (1957)

[22] Fujino, and Kawabata; J. Text. Mach. Soc. Japan, Japanese ed., 11, 11, 156 (1958)

[23] K. Shirakashi and T. Yamaguchi ; J. Soc. Text. \& Cellulose Ind., Japanese ed., 6, 141 (1950)

K. Shirakashi and M. Yamaguchi ; ibid., 7, 24,81 (1951) K. Shirakashi and M. Yamaguchi ; ibid., 8, 61, 198, 253 (1952)

[24] T. Nozaki, A. Aino, K. Ando and S. Hasegawa ; Reports of the Government Industrial Research Institute, Nagya, 2, 1 (1953)

[25] K. Hisada, T. Nozaki, Watanaba, K. Ando and Uenishi ; ibid., 2, 1 (1953)

K. Hisada; J. Text. Mach. Soc. Japan, Japanese ed., 6, 553 (1953)

K. Hisada; Reports of the Government Industrial Re. search Insiitrte, Nagoya, 4, 245 (1954) 
[26] K. Fujino; J. Text. Mach. Soc. Japan, Japanese ed., 1, 20 (1948)

[27] K. Mihira and H. Sugimoto; Unpublished.

[28] H. Takai ; Unpublished.

[29] K. Mihira; Reports of the Japan Cotton Technical Instituie, No. 30-2 (1957)

[30] J. Shimizu and S. Ishikawa; Unpublished.

[31] K. Fujino and T. Kawabata; J. Text. Mach. Soc. Japan, Japanese ed., 14, 2 (1961)

[32] M. Yamaguchi; ibid., 14, 15 (1961)

[33] K. Fujino and Y. Shimotsuma; Reports of the Japan Cotton Technical Institute, No. 47 (1955)

K. Fujino and Y. Shimotsuma; ibid., No. 65 (1956)

K. Fujino, Y. Shimotsuma, M. Shinagawa and Y. Komatsu; J. Text. Mach. Soc. Japan, Japanese ed., 10, 911 (1957) K. Fujino, Y. Shimotsuma, Sakaguchi and Aoki; ibid.

[34] S. Noda, S. Miura and Y. Matsumoto; ibid., 4, 627 (1951)

S. Noda, S. Miura and Y. Matsumoto; ibid, 6, 171 (1953)

[35] T. Takizawa, K. Imamura and M. Kobayashi; J. Soc. Text. \& Cellulose Ind., Japanese ed., 10, 287, 340, 403, 466 (1954)

[36] Kato and Ishihara; J. Text. Mach. Soc. Japan, Japanese ed., 5, 689 (1952)

[37] K. Fujino and A. Horikawa; ibid., 5, 612, 680 (1952) K. Fujino and A. Horikawa; ibid., 6, 10, 774 (1953)

[38] H. Uchida, T. Takizawa, M. Tabata, M. Kobayashi and S. Noda; Reports of Japan Cotton Technical Institute, No. 24 (1948)

[39] T. Ogawa; J. Text. Mach. Soc. Japan, Japanese ed., 6, 115 (1953)

T. Ogawa ; ibid., 8, 736 (1955)

[40] S. Watanabe; J. Text. Mach. Soc. Japan, Japanese ed., 8, 763 (1955)

[41] K. Shirakashi and M. Tabata; Reports of the Japan Cotton Technical Institute, No. 46 (1956)

K. Shirakashi, M. Yamaguchi and I. Toyoshima ; J. Text. Mach. Soc. Japan, Japanese ed., 6, 402, 493, 573 (1953)

[42] I. Kaino; J. Text. Mach. Soc. Japan, Japanese ed., 6, 106,136 (1953)

[43] S. Noda and M. Oe ; ibid., 8, 109, 176 (1955)

[44] S. Ishikawa and K. Higuchi; J. Soc. Text. \& Cellulose Ind., japanese ed., 8, 238, 296 (1952)

[45] H. Kamogawa and K. Higuchi; Reports of the Japan Cotton Technical Institute, No. 18 (1957)

[46] J. Shimizu; J. Text. Mach. Soc. Japan, Japanese ed., 12, 876 (1959)

S. Ishikawa and J. Shimizu; J. Soc. Text. \& Cellulose Ind., Japanese ed., 15, 461 (1959)

[47] T. Ogawa and S. Ishihara; "Draft theory and its practice (1) "The Textile Machinery of Japan, Osaka, Japan

[48] T. Yamagishi, H. Furuyama and H. Kuroe; J. Text. Mach. Soc. Japan, Japanese ed., 8, 521 (1955)

[49] W. Itani ; J. Text. Mach. Soc. Japan, Japanese ed., 9, 461, 809 (1956)

W. Itani : ibid., 10, 293 (1957)

W. Itani ; ibid., 11, 107, 186 (1958)
[50] T. Nakayama ; Bulletin of the Textile Research Institute, 9, 390, 434, 495 (1943)

T. Nakayama; Journal of the Textile Indusirial Society of Japan (Seni Kogyo Gakkai Shi) 9, 565 (1943)

T. Nakayama; J. Soc. Text. \& Cellulose Ind. Japanese ed., 1, 50 (1944)

[51] M. Amano; J. Soc. Text. \& Cellulose Ind., Japanese ed., 7, 418 (1951)

M. Amano; J. Text. Mach. Soc., Jadanese ed., 4, 182 (1951)

[52] S. Ishikawa and M. Tabata ; J. Soc. Text. \& Cellulose Ind., Japanese ed., 8, 544, 594 (1952)

S. Ishikawa and M. Tabata; ibid., 9, 457 (1953)

S. Ishikawa and M. Tabata ; ibid., 10, 212, 261, 344 (1954)

[53] K. Fujino and A. Horikawa; J. Text. Mach. Soc. Japan, Japanese ed., 5, 612, 680 (1952)

K. Fujino and A. Horikawa; ibid., 6, 10, 774 (1953)

K. Fujino and A. Horikawa; ibid., 8, 375 (1955)

[54] K. Hayakawa; J. Soc. Text. \& Cellulose Ind., Japanese ed., 6, 298, 363 (1950)

K. Hayakawa ; ibid, 8, 15 (1952)

K. Hayakawa ; ibid, 11, 78 (1955)

[55] Y. Narita ; J. Soc. Text. \& Cellulose Ind., Japanese ed., 7, 308 (1951)

[56] H. Uchida, T. Takizawa, et al.; J. Soc. Text. Cellulose Ind., Japanese ed., 6, 364, 427: 489 (1950)

H. Uchida, T. Takizawa ; ibid., 7, 13, 64, 527 (1951)

H. Uchida, T. Takizawa; ibid., 8, 235, 291, 340 (1952)

H. Uchida, T. Takizawa, et al.: ibid., 9, 71, 182, 303 (1953)

[57] K. Shirakashi and M. Yamaguchi; J. Soc. Tert. \& Cellulose Ind., Japanese ed., 8, 61 (1952)

[58] S. Ishikawa, M. Tabata and T. Okubo; ibid., 9, 17 (1953) S. Ishikawa, M. Tabata, T. Okubo and M. Kobayashi ; ibid., 11, 259 (1955)

[59] K. Mihira; J. Text. Mach. Soc. Japan, Japanese ed., 9, 225, 307 (1956)

[60] R. Hirako; ibid., 10, 25 (1957)

[61] S. Ishikawa, J. Shimizu and M. Haneda; Unpublished.

[62] K. Fuchino, S. Ueno and Terauchi : Unpublished.

[63] S. Ishikawa and J. Shimizu; J. Soc. Text. \& Cellulose Ind., Japanese ed., 11, 120 (1955)

[64] G. Osawa and Hashiba: Unpublished.

[65] S. Ishikawa and T. Kurusu; Unpublished.

[66] F. Murakami ; J. Text. Mach Soc. Japan, Japanese ed., 11, 10 (1958), 12, 861 (1959)

F. Murakami, T. Shoman and S. Kase; ibid., 12, 1 (1959)

[67] K. Mihira and H. Takeda; ibid., 13, 13 (1960)

K. Mihira and H. Takeda; ibid., 15, 176 (1962)

[68] B. Sato, M. Ihara and F. Miyashita; Reports of the Textile Research Institute, 47, (1958)

[69] J. Shimizu; J. Text. Mach. Soc. Japan, Japanese ed. 12, 872 (1959)

[70] S. Kawabata ; ibid., 12, 868 (1959)

[71] M. Uno; ibid. 